\title{
Effectiveness of multicomponent interventions on incidence of delirium in hospitalized older patients with hip fracture: a systematic review
}

\author{
Tarandeep Oberai, ${ }^{1}$ Kate Laver, ${ }^{2}$ Maria Crotty, ${ }^{2}$ Maggie Killington ${ }^{2}$ \\ and Ruurd Jaarsma ${ }^{1}$ \\ ${ }^{1}$ Department of Orthopedic Surgery and Trauma, College of Medicine and Public Health, Flinders University, Bedford Park, South Australia, Australia \\ ${ }^{2}$ Department of Rehabilitation, Aged and Extended Care, College of Medicine and Public Health, Flinders University, Bedford Park, South Australia, Australia
}

ABSTRACT

Background: Delirium is the most frequent complication among the hospitalized elderly with hip fracture. Although, delirium is associated with longer hospital stay, higher mortality rates, worse functional outcomes, and higher institutionalization rates yet health service planners have hugely ignored its existence. This review aims to identify the effectiveness of multicomponent interventions to prevent delirium in hospitalized elderly patients with hip fracture.

Methods: This review includes experimental, non-experimental, and observational studies. Electronic searches were conducted in MEDLINE, CINAHL, PsycINFO, Cochrane Central Register of Controlled Trials, Embase, and Web of science.

Results: After inclusion and exclusion criteria were applied, nine full text articles were included in the review. The studies reported the following effect on delirium: We pooled data regarding incidence of delirium from the three RCTs. The effect was in favor of the intervention group (odds ratio 0.64, 95\% CI 0.46-0.87). All three RCTs reported that duration of delirium was shorter in the intervention group than in the usual care group (mean 2.9 vs. 3.1 days, median 3 vs. 4 days, median 5.0 vs. 10.2 days). Four other studies reported on the duration of delirium with Milisen and colleagues reported shorter duration of delirium within the intervention group. Four studies reported on severity of delirium with two research groups reporting significant results.

Conclusion: Early engagement of multidisciplinary staff who addresses the risk factors of delirium as soon as the patient presents to the acute care environment is the key element of a successful delirium prevention program. Once delirium had developed, the multicomponent interventions did not appear to make a difference to the duration or severity of delirium.

Key words: Delirium-elderly patients, hip fracture, multi-component intervention, prevention

\section{Introduction}

Hip fractures, which are often a result of low energy trauma, are serious injuries commonly experienced by older people (Magaziner et al., 2000; Marks et al., 2003). Worldwide, about 1.5 million hip fractures occur each year (Hernlund et al., 2013). These injuries have a major impact not only on the person's long-term health, but also on

Correspondence should be addressed to: Tarandeep Oberai, Department of Orthopedic Surgery and Trauma, College of Medicine and Public Health, Flinders University, Bedford Park, South Australia 5042, Australia. Email: tarandeeptaran.oberai@sa.gov.au. Received 5 Jul 2017; revision requested 2 Nov 2017; revised version received 8 Nov 2017; accepted 12 Nov 2017. First published online 3 January 2018. informal carers, health services, and the community (Hirsch et al., 1990). Globally, the 30-day mortality after a neck of femur fracture is between $7 \%$ and $9 \%$ and the one-year mortality ranges from $22 \%$ to 30\% (Moran et al., 2005; Rae et al., 2007). Hip fractures also place a considerable burden upon the healthcare system because of the associated increase in morbidity. According to The REFReSH study group, total annual hospital costs associated with incident hip fractures in United Kindom were estimated at $£ 1.1$ billion (Leal et al., 2016).

During hospital admissions, these people are at risk of developing complications including functional, physical, and cognitive impairments (Hirsch et al., 1990). Poor general health, older 
age, cognitive impairment, and decreased activity level increase the risk of complications associated with hip fractures (Svensson et al., 1996; Liu et al., 2015). Studies have identified delirium as the most frequent complication among hospitalized older people and delirium is particularly common following a hip fracture (Gustafson et al., 1988; Brauer et al., 2000; Edlund et al., 2001). Delirium is a complex neuropsychiatric syndrome characterized by acute and fluctuating course, inattention, altered level of consciousness, and evidence of disorganized thinking (Marcantonio, 2011). Marcantonio et al. (2001) reported that 35$65 \%$ of patients who have undergone surgery for a neck of femur fracture repair suffered delirium post-operatively. A systematic review published in 2016 reported on risk factors for post-operative delirium following hip fracture repair. The results of a recent meta-analysis examining risk factors for delirium showed that patients with existing cognitive impairment, advancing age, living in an institution, heart failure, total hip arthroplasty, multiple comorbidities, and morphine use were more likely to experience delirium after hip surgery (Yang et al., 2017). Several studies have observed that patients presenting with delirium during the hospital stay have a worse prognosis, stay longer in the hospital, and have higher mortality rates, worse functional recovery, and higher institutionalization rates after hospital discharge (Francis et al., 1990; Rockwood et al., 1999; McCusker et al., 2001). Although delirium is known to be associated with poor clinical outcomes, health service planners and practitioners have largely accepted delirium as a common presentation (Inouye et al., 1999).

A number of studies have investigated interventions to prevent delirium, which can be grouped into multicomponent therapies and single interventions (Kalisvaart et al., 2005; Overshott et al., 2008; Bjorkelund et al., 2010; de Jonghe et al., 2014). The majority of single intervention studies focus on the impact of pharmacological interventions (Kalisvaart et al., 2005; Overshott et al., 2008; de Jonghe et al., 2014). Effectiveness studies on the use of pharmacological interventions for delirium prevention show mixed results (Kalisvaart et al., 2005; Overshott et al., 2008; de Jonghe et al., 2014). Randomized controlled trials (RCTs) investigating the effectiveness of drugs such as haloperidol and melatonin for prevention of delirium in hip fracture patients have been conducted (Kalisvaart et al., 2005) but so far have failed to change the incidence of delirium (Kalisvaart et al., 2005; de Jonghe et al., 2014). On the other hand, studies exploring the effect of multicomponent interventions have shown promising results (Bjorkelund et al., 2010). Multicomponent interventions refer to more than one strategy to address the range of risk factors associated with delirium that can include pharmacological as well as non-pharmacological interventions; a number of studies suggest this approach is effective (Kalisvaart et al., 2005; Bjorkelund et al., 2010).

A Cochrane review published in 2007 examined interventions for preventing delirium in various older patients. Only one of the included studies involved people following hip fracture repair; in this study it was suggested that proactive geriatric consultation can reduce incidence and severity of delirium (Siddiqi et al., 2007). In 2013, Thomas et al. published a systematic review regarding the effectiveness of non-pharmacological multicomponent interventions for delirium prevention; participants in the study comprised any elderly patient admitted to a non-intensive care unit. The findings of this review suggested that multicomponent interventions have a potential to reduce risk of delirium (Thomas et al., 2014). More recently, two systematic reviews were undertaken on the same interventions but this time involving elderly patients with various medical conditions. As none of the reviews are specific to hip fracture population, a systematic review investigating effect of multicomponent interventions on incidence of delirium is warranted (Martinez et al., 2015; Hshieh et al., 2015).

\section{Methods}

\section{Inclusion criteria}

TYPES OF PARTICIPANTS

This review considered studies that included hospitalized patients aged 65 years and over, who sustained a hip fracture, irrespective of the mechanism of injury or method of treatment.

\section{TYPES OF INTERVENTION}

Studies were included if they evaluated the effect of multicomponent interventions on incidence of delirium. A multicomponent intervention refers to the use of more than one strategy which can include but is not limited to: the use of specialized clinical staff/volunteers, geriatric/psychiatric consultation, staff education, patient orientation, addressing visual and hearing needs, sleep enhancement, medication review, hydration and nutrition, early mobilization, pain management, addressing bowel and bladder functions and prevention, and treatment of medical complications. This review did not exclude studies based on the dose of (e.g. intensity, frequency, and duration), or who delivered, the intervention. 


\section{TYPES OF COMPARATORS}

This review considered studies where multicomponent interventions had been compared to single interventions or usual care or no intervention.

\section{TyPES OF OUTCOMES}

Studies were eligible for inclusion if they measured incidence of delirium as a primary outcome. Only studies which determined the presence of delirium using standardized criteria or a validated tool (such as but not limited to Confusion Assessment Method (CAM), Mental Status Questionnaires, and Mini-Mental State Examination (MMSE)) were included. Where reported, data regarding other outcomes such as discharge destination, length of stay, cognitive function, functional ability, and readmission were also extracted and presented in this review.

\section{TYPES OF STUDIES}

This review considered experimental studies, which presented information on an intervention group and information from a control group. This included RCTs, non- RCTs, and before and after intervention studies. This review also included observational studies such as prospective and retrospective cohort studies and case control studies as long as there was a control group.

\section{SEARCH STRATEGY}

The search strategy was designed to find both published and unpublished studies. A three-step search strategy was utilized in this review. An initial limited search of MEDLINE and CINAHL was undertaken followed by analysis of the text words contained in the title and abstract, and of the index terms used to describe the article. A second search using all identified keywords and index terms was then undertaken across all included databases. Third, the reference list of all identified articles was searched for additional studies. Only studies published in the English language were considered for inclusion in this review. The search was limited to studies published between 1999 to the present as multicomponent intervention strategies for the prevention of delirium began to appear in the published literature during this time (Morency, 1990; Zimberg and Berenson, 1990; Wanich et al., 1992; Holt, 1993; Bleasdale and George, 1996).

The databases searched via EBSCO and OVID platforms included MEDLINE, CINAHL, PsycINFO, Cochrane Central Register of Controlled Trials, Embase, and Web of science. Please refer to Supplemental File 1 for complete results and search terms used.

\section{Data collection and analysis}

\section{Selection of studies}

The initial search yielded 2,247 titles and abstracts from electronic searches (Figure 1). After duplicates were removed, 1,176 articles were reviewed for initial screening and 176 for next stage of screening. After inclusion and exclusion criteria were applied, nine full text articles were included in the review.

\section{Assessment of quality}

The methodological quality of the studies was assessed by two independent reviewers (TO and LL) using standardized critical appraisal instruments from the Joanna Briggs Institute MetaAnalysis of Statistics Assessment and Review Instrument (JBI-MAStARI). Any disagreements that arose between the reviewers were resolved through discussion.

\section{Data extraction}

Data was extracted from papers included in the review using the standardized data extraction tool from JBI-MAStARI. The data extracted included specific details about the populations, interventions (e.g. type, intensity, and duration), outcomes, and study methods. Data extraction was carried out by one reviewer with verification by another reviewer to minimize bias and potential errors in data extraction. Pooling of results was not possible due to methodological differences hence the findings have been presented in narrative form.

\section{Results}

\section{Description of the studies}

Nine studies met the inclusion and exclusion criteria. Out of the nine studies, three were RCTs (Marcantonio et al., 2001; Lundstrom et al., 2007; Watne et al., 2014). The total number of participants in the nine included studies were 1,$889 ; 874$ in the intervention group; and 1,015 in the control groups. Participants in the studies comprised of $75 \%$ females and $25 \%$ males. The average age of the participants in all the included studies ranged from 78 to 85 years. All the patients sustained various forms of proximal hip fracture. The studies originated from different parts of the world, including North America, Europe, and Australia. The patients included in the studies were mostly treated in orthopedic or geriatric ward settings. Bjorkelund et al. (2010) did not include patients who had prevalent delirium on admission. Characteristics of included studies are described in more detail in Table 1. 

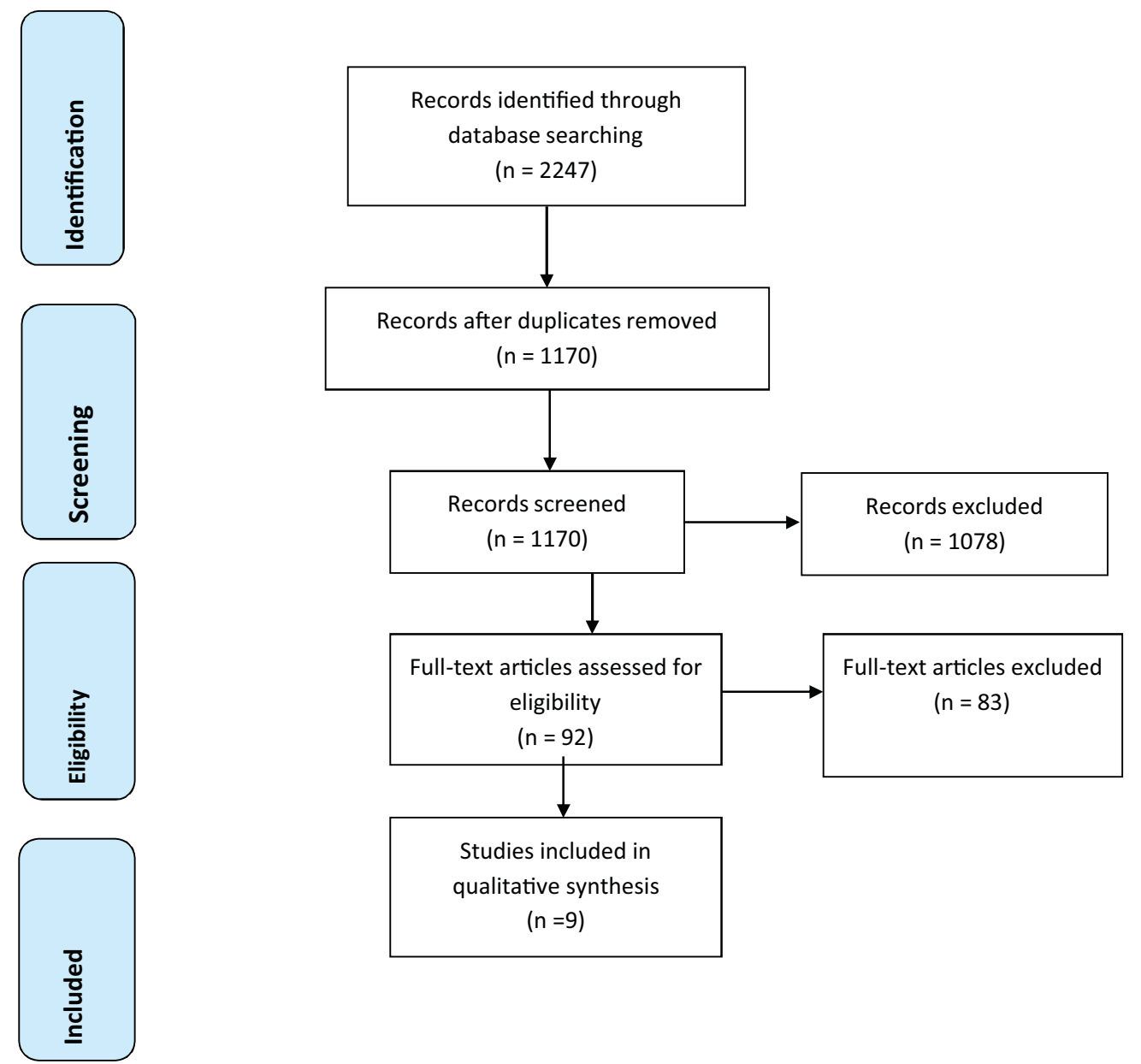

Figure 1. (Colour online) Schema of the stages of searching and inclusion/exclusion of studies for the review.

The multicomponent interventions in the studies included common themes (Table 2) and four studies implemented consultation/assessment by a geriatrician. Marcantonio et al. (2001) implemented multicomponent interventions following proactive geriatric consultation of individuals in intervention group which began pre-operatively or within $24 \mathrm{~h}$ of surgery. Wong et al. (2005), Watne et al. (2014) and Deschodt et al. (2012) used the same model where recommendations were based on work done by Marcantonio et al. following a consultation by a geriatric registrar that formed a basis of treatment planning. The team consisted of geriatrician, nurse, physiotherapist, and occupational therapist. Milisen et al. (2001) and Lundstrom et al. (2007) focused their interventions not only on team work but also on staff education. Milisen et al. (2001) implemented a nurseled interdisciplinary intervention program where nurses were educated on early recognition and diagnosing delirium as they considered it essential for proper treatment. Consultative services were provided by a delirium resource nurse, a geriatric nurse specialist or a psychogeratrician and the model of care was based on work done by Inouye and colleagues. Inouye et al. (1993) Bjorkelund et al. (2010) implemented a new program including pre-hospital, perioperative treatment and care. Lundstrom et al. (1999) conducted another study which also focused on staff education in caring, rehabilitation, teamwork, knowledge about delirium, risk factors prevention, and treatment. HolroydLeduc et al. (2010) studied the application of a clinical decision support system that included an enhanced version of the hip fracture order set. The order set included elements of the multicomponent interventions followed in the studies by Marcantonio et al. (2001) and Lundstrom et al. (2007)

Outcomes examined included incidence of delirium, duration and severity of delirium, cognitive function, activities of daily living, length of hospital stay, institutionalization at discharge and mortality. Although, all studies examined incidence of delirium, there was heterogeneity in both the statistical measures of frequency and diagnostic methods used. 
Table 1. Characteristics of the included studies

\begin{tabular}{|c|c|c|c|c|c|c|}
\hline AUTHORS & YEAR & LOCATION & SETTING & METHODOLOGY & $\begin{array}{l}\text { PREVALENT } \\
\text { DELIRIUM } \\
\text { EXCLUDED ON } \\
\text { ADMISSION }\end{array}$ & $\begin{array}{l}\text { CONTROL } \\
\text { GROUP }\end{array}$ \\
\hline $\begin{array}{l}\text { Holroyd- } \\
\text { Leduc } \\
\text { et al. }\end{array}$ & 2010 & Canada & $\begin{array}{l}\text { Orthopedic unit } \\
\text { in two hospitals }\end{array}$ & $\begin{array}{l}\text { Prospective } \\
\text { cohort study }\end{array}$ & $\begin{array}{l}\text { Unable to } \\
\text { determine }\end{array}$ & $\begin{array}{l}\text { Pre }=\text { implement- } \\
\text { ation control } \\
\text { group }\end{array}$ \\
\hline $\begin{array}{l}\text { Lundstrom } \\
\text { et al. }\end{array}$ & 2007 & Sweden & $\begin{array}{l}\text { Specialized } \\
\text { geriatric unit } \\
\text { and } \\
\text { conventional } \\
\text { orthopedic unit }\end{array}$ & $\begin{array}{l}\text { Randomized } \\
\text { control trial }\end{array}$ & No & Usual care \\
\hline $\begin{array}{l}\text { Lundstrom } \\
\text { et al. }\end{array}$ & 1999 & Sweden & $\begin{array}{l}\text { Geriatric } \\
\text { rehabilitation } \\
\text { unit }\end{array}$ & $\begin{array}{l}\text { Prospective } \\
\text { cohort }\end{array}$ & No & $\begin{array}{l}\text { Historic control } \\
\text { group }\end{array}$ \\
\hline $\begin{array}{l}\text { Bjorkelund } \\
\text { et al. }\end{array}$ & 2010 & Sweden & Orthopedic unit & $\begin{array}{l}\text { Non-randomized } \\
\text { control trial }\end{array}$ & Yes & $\begin{array}{l}\text { Pre-intervention } \\
\text { control group }\end{array}$ \\
\hline $\begin{array}{l}\text { Marcantonio } \\
\text { et al. }\end{array}$ & 2001 & $\begin{array}{l}\text { United } \\
\text { States }\end{array}$ & $\begin{array}{l}\text { Academic tertiary } \\
\text { medical center }\end{array}$ & $\begin{array}{l}\text { Randomized } \\
\text { control trial }\end{array}$ & No & Usual care \\
\hline Milisen et al. & 2001 & Belgium & Two trauma units & $\begin{array}{l}\text { Non-randomized } \\
\text { control trial } \\
\text { (prospective } \\
\text { before/after } \\
\text { design) }\end{array}$ & No & Usual care \\
\hline Wong et al. & 2005 & Australia & Orthopedic unit & $\begin{array}{l}\text { Prospective } \\
\text { cohort }\end{array}$ & No & $\begin{array}{l}\text { Historic control } \\
\text { group }\end{array}$ \\
\hline Watne et al. & 2014 & Norway & $\begin{array}{l}\text { Acute geriatric } \\
\text { ward and } \\
\text { orthopedic } \\
\text { ward }\end{array}$ & $\begin{array}{l}\text { Randomized } \\
\text { control trial }\end{array}$ & No & Usual care \\
\hline Deschodt et al. & 2012 & Belgium & Two trauma units & $\begin{array}{l}\text { Non-randomized } \\
\text { control trial }\end{array}$ & No & Usual care \\
\hline
\end{tabular}

\section{Risk of bias in included studies}

Studies varied in their methodological quality. RCTs were considered high quality for all items although participants and personnel were not blinded. All three RCTs (Marcantonio et al., 2001; Lundstrom et al., 2007; Watne et al., 2014) included blinded assessment of outcomes. The three non-randomized trials (Milisen et al., 2001; Bjorkelund et al., 2010; Deschodt et al., 2012) were also considered high quality as all the items were reported on with the exception of multiple measurements pre- and post-exposure. It was not possible to comment on the quality of the two studies (Wong et al., 2005; Holroyd-Leduc et al., 2010) as the methodology used in these studies has been poorly described.

\section{Effect of interventions}

We only considered randomized controlled studies for inclusion in a meta-analysis. We were able to conduct meta-analysis for one outcome (incidence of delirium) as other outcomes were not reported in a way that is appropriate for pooling. The impact of multicomponent interventions on outcomes is described in Table 3.

\section{Primary outcome}

\section{Incidence of delirium}

We pooled data regarding incidence of delirium from the three RCTs (Lundstrom et al., 2007; Marcantonio et al., 2001; Watne et al., 2014). The effect was in favor of the intervention group (odds ratio $0.64,95 \%$ CI $0.46-0.87$ ) (see Figure 2). The remaining six studies all reported that incidence of delirium was reduced in the intervention group; the difference in incidence of delirium between groups ranged from only $2 \%$ in one study (Holroyd-Leduc et al., 2010) to $31 \%$ in another (Lundstrom et al., 1999).

\section{Duration of delirium}

Six studies reported on duration of delirium (Lundstrom et al., 1999; Milisen et al., 2001; 


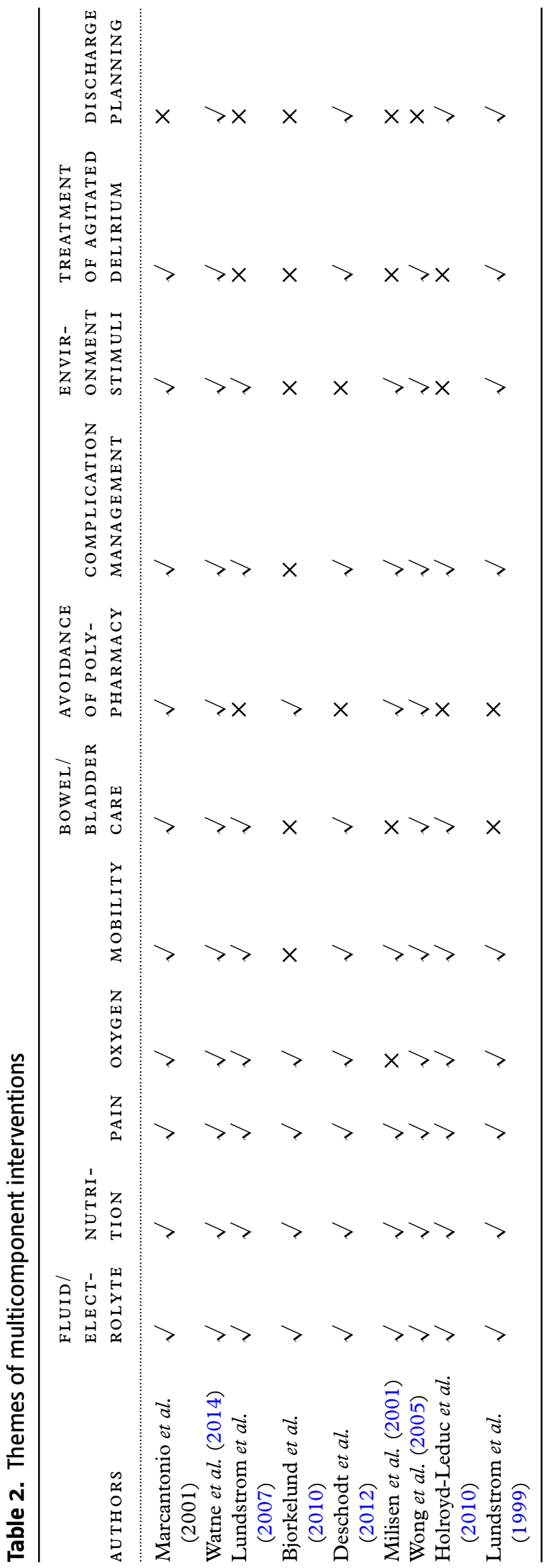

Marcantonio et al., 2001; Lundstrom et al., 2007; Deschodt et al., 2012; Watne et al., 2014). All three randomized trials reported that the duration of delirium was shorter in the intervention group than in the usual care group (mean 2.9 vs. mean 3.1 days(Marcantonio et al., 2001); median 3 vs. 4 days (Watne et al., 2014); median 5.0 vs. 10.2 days) (Lundstrom et al., 2007). Data from these three studies could not be pooled due to the way in which they were reported. The other three/four studies reported on the duration of delirium with Milisen and colleagues (2001) reporting statistically significantly shorter duration of delirium within the intervention group (median $=1$ day, $\mathrm{IQR}=1$ ) compared with the nonintervention cohort) median $=4$ days, $\mathrm{IQR}=5.5$ ). Two other studies (Bjorkelund et al., 2010 and Lundstrom et al., 1999) reported that participants in the control group had longer lasting delirium than those in the intervention group however the differences between groups were not found to be statistically significant. Deschodt and colleagues found no differences between groups.

\section{Severity of delirium}

Four studies reported on severity of delirium (Milisen et al., 2001; Marcantonio et al., 2001; Deschodt et al., 2012; Watne et al., 2014). Marcantonio and colleagues reported that a smaller proportion of participants within their intervention group experienced severe delirium (12\% vs. $29 \%)$, whereas Watne et al. (2014) did not find a statistically significant difference between groups. Milisen and colleagues (2001) reported less severe symptoms of delirium were experienced by participants within the intervention group (ranges from 3.82 to 1.91 vs. 6.92 to 5.0 ) and Bjorkelund et al. (2010) failed to detect a statistically significant difference between groups.

\section{Secondary outcomes}

\section{Discharge destination}

Participant discharge destination was reported in five studies (Lundstrom et al., 1999; Marcantonio et al., 2001; Wong et al., 2005; Holroyd-Leduc et al., 2010; Watne et al., 2014). None of the studies were able to show a significant improvement in outcome in terms of more desirable discharge destination. Methods of reporting on this outcome varied across the studies. Four studies reported whether or not the person was discharged to a care institution while Lundstrom and colleagues (1999) reported on the patients who were discharged to independent living. The difference between 
Table 3. Effect of interventions

\begin{tabular}{|c|c|c|c|c|c|c|c|c|c|}
\hline & $\begin{array}{l}\text { Marcantonio } \\
\quad 2001 \\
N=126 \\
I=62 \\
U=64\end{array}$ & $\begin{array}{l}\text { Watne } 2014 \\
N=329 \\
I=163 \\
U=166\end{array}$ & $\begin{array}{l}\text { Lundstrom } \\
\quad 2007 \\
N=199 \\
I=102 \\
U=97\end{array}$ & $\begin{array}{l}\text { Deschodt } \\
\quad 2012 \\
N=171 \\
I=94 \\
U=77\end{array}$ & 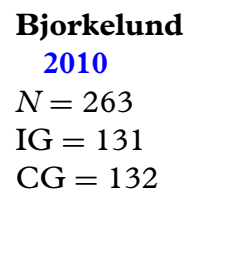 & $\begin{array}{l}\text { Holroyd } 2010 \\
N=134 \\
I=64 \\
C=70\end{array}$ & $\begin{array}{l}\text { Wong } 2005 \\
N=99 \\
\text { Baseline }=28 \\
\text { Post- } \\
\quad \text { intervention } \\
\quad=71\end{array}$ & $\begin{array}{l}\text { Milisen } 2001 \\
N=120 \\
I=60 \\
U=60\end{array}$ & $\begin{array}{l}\text { Lundstrom } \\
1999 \\
I=49 \\
\text { CG1 }=111 \\
\text { CG2 = } 103\end{array}$ \\
\hline $\begin{array}{l}\text { Incidence of } \\
\text { delirium }\end{array}$ & $\begin{array}{l}\text { CAM } \\
I=20 / 62=32 \% \\
U=32 / 64=50 \%\end{array}$ & $\begin{array}{l}\text { CAM } \\
I=80 / 163 \\
49 \% \\
U=86 / 166 \\
53 \%\end{array}$ & $\begin{array}{l}\text { MMSE } \\
I=56 / 102 \\
54.9 \% \\
U=73 / 97 \\
75.3 \%\end{array}$ & $\begin{array}{l}\text { CAM } \\
I=35-37.2 \% \\
U=41-53.2 \%\end{array}$ & $\begin{array}{l}\text { OBS scale } \\
\mathrm{IG}=29 / 131 \\
\quad(22.1 \%) \\
\mathrm{CG}=45 / 132 \\
(34.1 \%)\end{array}$ & $\begin{array}{l}\text { CAM } \\
I=20 / 64 \\
\quad(31 \%) \\
U=23 / 70 \\
(33 \%)\end{array}$ & $\begin{array}{l}\text { CAM } \\
I=9 / \\
\quad 71=12.7 \% \\
U=10 / 28 \\
\quad(35.7 \%)\end{array}$ & $\begin{array}{l}\text { CAM } \\
I=12=20 \% \\
U=14 \\
\quad=23.3 \%\end{array}$ & $\begin{array}{l}\text { OBS scale } \\
I=30.6 \% \\
\text { CG } 1=61.3 \% \\
\text { CG } 2=47.6 \%\end{array}$ \\
\hline $\begin{array}{l}\text { Duration of } \\
\text { delirium }\end{array}$ & $\begin{array}{l}\text { Days Mean } \pm \\
\text { SD } \\
I=2.9 \pm 2.0 \\
U=3.1 \pm 2.3\end{array}$ & $\begin{array}{l}\text { Median, IQR } \\
I=3(2-7) \\
U=4(2-6)\end{array}$ & $\begin{array}{l}\text { Median } \pm \text { SD } \\
I=5.0 \pm 7.1 \\
\quad \text { days } \\
U=10.2 \pm \\
13.3 \text { days }\end{array}$ & $\begin{array}{l}\text { Days } \\
I=1 \text { day } \\
\quad(\mathrm{IQR}=1-5)\end{array}$ & $\begin{array}{c}\leq 1 / \geq 2 \text { days } \\
\text { IG }=14 \\
(10.7 \%) / \\
15(11.5 \%) \\
\text { CG }=23 \\
(17.4 \%) / \\
22(16.7 \%)\end{array}$ & - & - & $\begin{array}{l}\text { Days me- } \\
\text { dian(IQR) } \\
I=M=1 \text { day, } \\
\text { IQR }+1 \\
U=M=4 \\
\text { days, } \\
\text { IQR }=5.5\end{array}$ & $\begin{array}{l}\text { Days } \geq 7 \text { days } \\
I=16.3 \% \\
\text { CG } 1=39.6 \% \\
\text { CG } 2=29.1 \%\end{array}$ \\
\hline $\begin{array}{c}\text { Severity of } \\
\text { delirium }\end{array}$ & $\begin{array}{l}\text { MDAS } \\
I=7 / 60=12 \% \\
U=18 / 62(29 \%)\end{array}$ & $\begin{array}{l}\text { MDAS } \\
\text { Median, } \\
\text { IQR } \\
I=21.5 \\
(15.3-25) \\
U=20 \\
(13.8-26)\end{array}$ & - & $\begin{array}{l}\text { Delirium } \\
\text { index } \\
\text { No significant } \\
\text { difference, } \\
P=0.51\end{array}$ & $\begin{array}{c}\text { OBS max } \\
\text { score } \leq 6 / \geq 7 \\
\text { IG }=105 \\
(80.2 \%) / \\
26(19.8 \%) \\
\text { CG }=97 \\
(73.5 \% / \\
35(26.5 \%)\end{array}$ & - & - & $\begin{array}{l}\begin{array}{l}\text { Variant of } \\
\text { CAM }\end{array} \\
I=3.82 \\
\mathrm{SD}=2.8-1.92 \\
\mathrm{SD}=2.3 \\
U=6.92 \\
\mathrm{SD}=2.8-5.0 \\
\mathrm{SD}=3.1\end{array}$ & - \\
\hline $\begin{array}{l}\text { Discharge } \\
\text { destination }\end{array}$ & $\begin{array}{l}\text { To NH or rehab } \\
\text { home } \\
I=92 \% \\
U=88 \%\end{array}$ & $\begin{array}{l}\text { To NH at } 4 \\
\text { months after } \\
\text { surgery } \\
I=19(16 \%) \\
U=18(15 \%)\end{array}$ & - & & - & $\begin{array}{l}\text { To long-term } \\
\quad \text { care } \\
I=4 / 64(6 \%) \\
U=9 / 70 \\
(13 \%)\end{array}$ & $\begin{array}{l}\text { To high care } \\
\text { level } \\
I=17 / 71 \\
(23.9 \%) \\
U=7 / 28 \\
(25.0 \%)\end{array}$ & & $\begin{array}{l}\text { To } \\
\text { independent } \\
\text { living } \\
I=89.3 \% \\
\text { CG } 1=62.3 \% \\
\text { CG } 2=53.4 \%\end{array}$ \\
\hline LOS & $\begin{array}{l}\text { Median } \pm \mathbf{I Q R} \\
=5 \pm 2 \text { days in } \\
\text { both groups }\end{array}$ & $\begin{array}{l}\text { Median IQR } \\
I=11(8-15) \\
U=8(4.8-11)\end{array}$ & $\begin{array}{c}\text { Mean } \pm \mathbf{S D} \\
I=28 \pm 17.9 \\
\quad \text { days } \\
U=38.0 \pm \\
40.6 \text { days }\end{array}$ & & - & $\begin{array}{l}\text { Median days } \\
\quad \text { (range) } \\
I=12(10-21) \\
U=14(9-21)\end{array}$ & $\begin{array}{l}\text { Median, } \\
\text { range } \\
I=10(2-44) \\
U=8(3-41)\end{array}$ & $\begin{array}{l}\text { Median } \pm \\
\text { IQR } \\
I=13.5 \\
\mathrm{IQR}=3.75 \\
U=14, \\
\mathrm{IQR}=5\end{array}$ & $\begin{array}{l}I=12.5 \text { days } \\
\text { (incl. rehab } \\
\text { time) } \\
\text { CG1 }=17.4 \\
\text { days (ortho } \\
\text { ward) } \\
\text { CG2 }=11.6 \\
\text { days (ortho } \\
\text { ward) }\end{array}$ \\
\hline
\end{tabular}




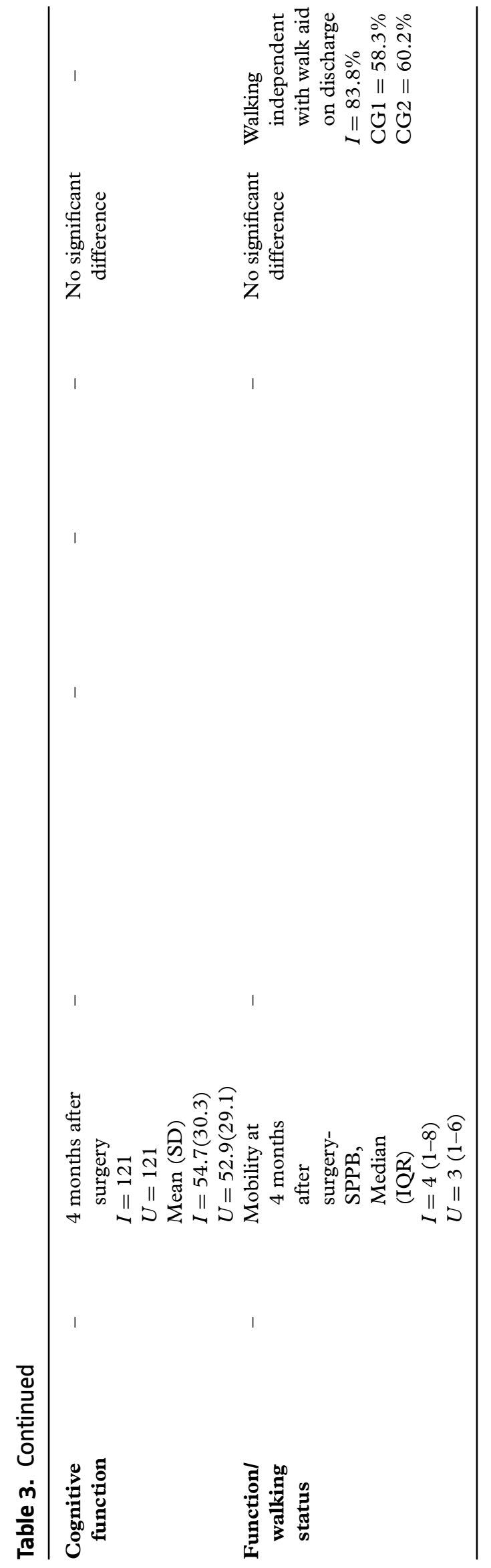

intervention and control group participants who were discharged to institutionalized care ranged from only $1 \%$ in one study (Watne et al., 2014) to $7 \%$ in another study (Holroyd-Leduc et al., 2010)

\section{Length of hospital stay}

Length of hospital stay was reported in seven studies (Milisen et al., 2001; Marcantonio et al., 2001; Wong et al., 2005; Lundstrom et al., 2007; Holroyd-Leduc et al., 2010; Watne et al., 2014). Two (Marcantonio et al., 2001; Watne et al., 2014) of the randomized trials reported no significant differences between groups whereas Lundstrom and colleagues (2007) found significantly shorter length of stay in the intervention group (mean 28 (SD 17.9) vs. mean 38 (40.6) days). Of the remaining studies, three reported no significant differences, whereas Lundstrom et al. (1999) found significant shorter post-operative hospitalization was experienced by the patients in the intervention group (12.5 days including rehabilitation time vs. length of stay excluding the rehabilitation time in patients of control group 1 and control group 2 was 17.4 and 11.6 days (Lundstrom et al., 1999). Interestingly, Watne et al. (2014) reported that the patients in the intervention group within their RCT had longer length of stay by three days, however, this was not statistically significant.

\section{Cognitive function}

Cognitive function was reported in three studies (Milisen et al., 2001; Deschodt et al., 2012; Watne et al., 2014) with only one (non-randomized) study (Deschodt et al., 2012) demonstrating significantly higher proportion of participants experiencing cognitive decline at discharge within the control group than those allocated to intervention group (38.7\% vs. $22.6 \%$ ).

\section{Functional and mobility status}

Only three studies (Lundstrom et al., 1999; Milisen et al., 2001; Watne et al., 2014) reported on functional or mobility status of the patients. Only Lundstrom and colleagues (1999) suggested that a significantly higher number of participants were walking independently with walking aids on discharge $(83.8 \%$ within the intervention group and $58.3 \%$ \& $60.2 \%$ within Control group 1 and control group 2 , respectively).

\section{Discussion}

This review included nine studies with evidence that multicomponent intervention strategies have positive effects on delirium in patients with hip 


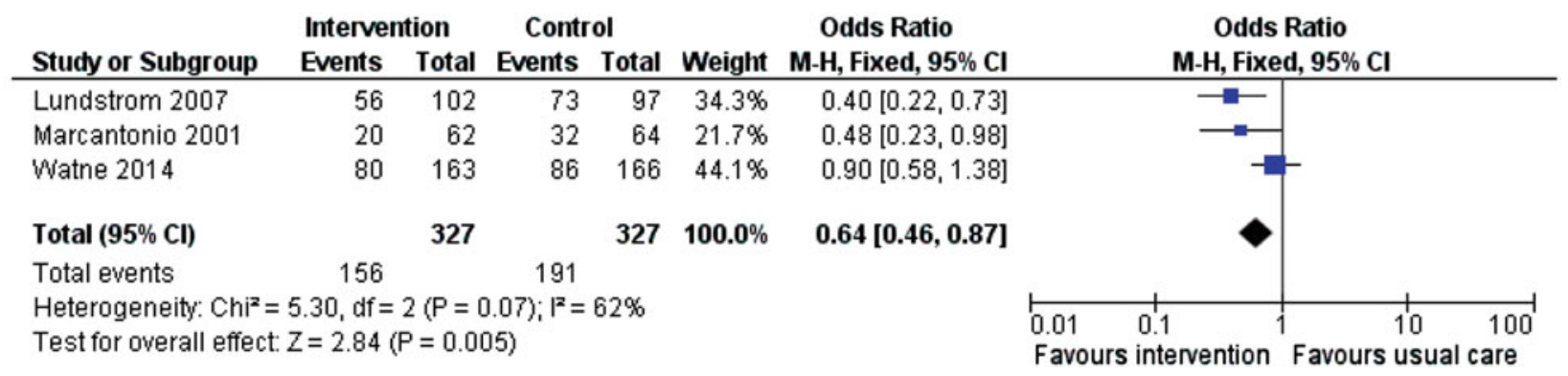

Figure 2. (Colour online) Multicomponent intervention to prevent delirium vs. usual care: effect on incidence of delirium.

fracture. Benefits appear to be predominantly in reduced incidence. Only two studies (Milisen et al., 2001; Lundstrom et al., 2007) suggested shorter duration of delirium and one study suggested less severe symptoms of delirium. One study (Lundstrom et al., 1999) demonstrated reduced length of hospital stay and a larger proportion of the participants returning to their previous living conditions. The same study also reported a higher proportion of patients were walking independently with a walking aid on discharge. Only one study (Deschodt et al., 2012) demonstrated a significant difference in cognitive decline at discharge in between the intervention and control group.

All included studies initiated assessment/ consultation within $24 \mathrm{~h}$ of admission which then formed the basis for early care planning. Once delirium had developed, the multicomponent interventions did not appear to make a significant difference to the duration or severity of delirium.

All of the studies provided information about the multidisciplinary teamwork or clinical leadership in implementing the interventions. The common theme appears to be of early diagnosis and early management by specialist geriatric clinical staff. In general early assessment by geriatricians is associated with better outcomes and many national guidelines now include this as best practice (city Australian guideline and UK NICE guideline (Chesser et al., 2011; Chehade and Taylor, 2014). Besides this, clinical staff consistently implemented targeted protocols/guidelines/electronic care pathways that addressed cognition, mobility, sleep/rest, hydration, nutrition, pain management, bowel and bladder function, along with prevention and management of any post-operative complications. The multicomponent interventions were varied and involved multiple strategies and disciplines but all the strategies addressed the significant risk factors in development of delirium in hip fracture population. A variety of clinical staff were involved, including doctors, nurses, physiotherapists, occupational therapist, and social workers. All studies included components such as proactive consultation with a geriatrician and individual care planning.
The limited number of studies (including only three randomized trials) means that it is difficult to draw conclusions about which participant group may benefit most from multicomponent intervention. In the subgroup analyses conducted by Marcantonio and colleagues, interventions were more effective in reducing delirium among patients without prefracture dementia or activities of daily living impairment. Interventions may have been more effective within this subgroup because of timely diagnosis whereas delay in diagnosis of the underlying cause may contribute to the poorer outcomes in patients experiencing delirium superimposed on dementia (Fick and Foreman, 2000). The delay in diagnosis is maybe due to lack of clarity whether delirium just uncovers a previously unrecognized dementia or if leads to cognitive decline that increases the risk of developing dementia (Fick et al., 2002). Some medications like benzodiazepines have been associated with cause of delirium in persons with dementia (Lerner et al., 1997) and both delirium and dementia have been known to have several common pathophysiological features (Eikelenboom and Hoogendijk, 1999). Given these complexities, it possibly further delays the timely diagnosis of delirium superimposed on dementia. In our systematic review due to the relatively small sample size within these subgroups, these effects were not statistically significant. Another study (Lundstrom et al., 2007) demonstrated significant difference in duration of post-operative delirium in patients with dementia in the intervention group patients.

None of the studies assessed the economic impact of shorter length of hospital stay. We believe that if economic evaluations were performed in the studies that reported on shorter length of hospital stay this could have added up to significant figure as acute care hospital environment is highly expensive. Study conducted by REFReSH group reported that the hospitalization costs associated with each admission for hip fracture were $£ 8663$. Only one study (Wong et al., 2005) reported that expense of the intervention as the registrars (of geriatric specialty) spent considerably more time (estimated 
at an extra of $3 \mathrm{~h}$ per day) with the patients than they had before the project started.

This review supports the findings of other reviews that multicomponent interventions are effective in reducing incidence of delirium. However, none of these reviews are specific to hip fracture patients and given that this patient group has a higher level of risk and a different set of precipitating risk factors for delirium and may therefore require a distinct set of interventions compared to other older patient groups, this systematic review will add value to the existing literature.

Within this review, most of the included studies were at risk of bias due to lack of randomization and blinding. Although most studies reported the benefits of multicomponent intervention, it is difficult to make assumptions about which particular approach is most beneficial. For example, which components are most likely to be beneficial or whether one particular multicomponent approach is superior to others. Additionally, the variability in the components of the programs means that there is a limitation for accurate replication.

\section{Implications for practice}

Early diagnosis is the most effective strategy to prevent delirium. To decrease the incidence of delirium, all hip fracture patients admitted to acute care setting should have preventative interventions, including review by geriatricians initiated as soon as soon as possible. Once delirium develops the multicomponent intervention strategies have limited efficacy in minimizing duration and severity of delirium. Prevention of delirium before its onset is of high importance in order to keep patients with hip fracture physically, functionally, cognitively independent as well as safely discharge them to their pre-injury place of residence. Educating staff on the importance of early screening for delirium is a valuable exercise as screening will prompt early management of risk factors.

\section{Implications for research}

More translational evidence on the best way to implement use of delirium prevention protocols is needed to assist clinicians. In addition, economic evaluations conducted alongside randomized trials would provide useful information which may convince clinical staff and policy-makers to invest more in delirium prevention.

\section{Conclusion}

In summary, early engagement of multidisciplinary staff particularly geriatricians who address the risk factors of delirium as soon as the patient present to the acute care environment is the key element of a successful delirium prevention program. The studies do not address which components within a program provide the most benefit for delirium prevention or management yet this systematic review reveals that people with hip fracture who received multicomponent interventions had a significantly lower risk of developing delirium as compared to those who did not.

\section{Conflict of interest}

None.

\section{Description of author's roles}

T. Oberai - designed the review, followed PRISMA guidelines completed the review, wrote the paper. K. Laver - assisted with data extraction, metaanalysis, narrative synthesis, and writing the paper. M. Killington - assisted with narrative synthesis of the studies. M. Crotty - clinical expertise in geriatrics and assistance with writing the paper. R. Jaarsma - designing the review and providing orthopedic clinical expertise.

\section{Acknowledgments}

We are thankful to Dr Lucylynn Lizarondo, who was the second reviewer in the critical appraisal process.

\section{Supplementary material}

To view supplementary material for this article, please visit https://doi.org/10.1017/ S1041610217002782

\section{References}

Bjorkelund, K. B., Hommel, A., Thorngren, K. G., Gustafson, L., Larsson, S. and Lundberg, D. (2010). Reducing delirium in elderly patients with hip fracture: a multi-factorial intervention study. Acta Anaesthesiologica Scandinavica, 54, 678-688. doi: 10.1111/j.1399-6576.2010.02232.x

Bleasdale, S. and George, J. (1996). Managing delirium in elderly people. Elder Care, 8, 13-14.

Brauer, C., Morrison, R. S., Silberzweig, S. B. and Siu, A. L. (2000). The cause of delirium in patients with hip fracture. Archives of Internal Medicine, 160, 1856-1860.

Chehade, M. and Taylor, A. (2014). Australian and New Zealand guideline for hip fracture care-improving outcomes in hip fracture management of adults. New South Wales, 
Australia: Australian and New Zealand Hip Fracture Registry (ANZHFR) Steering Group.

Chesser, T., Handley, R. and Swift, C. (2011). New NICE guideline to improve outcomes for hip fracture patients. Injury, 42, 727-729.

de Jonghe, A. et al. (2014). Effect of melatonin on incidence of delirium among patients with hip fracture: a multicentre, double-blind randomized controlled trial. CMAF, 186, E547-556. doi: 10.1503/cmaj.140495

Deschodt, M. et al. (2012). Preventing delirium in older adults with recent hip fracture through multidisciplinary geriatric consultation. Fournal of the American Geriatrics Society, 60, 733-739. doi: https://doi.org/10.1111/j.1532-5415.2012.03899.x

Edlund, A., Lundstrom, M., Brannstrom, B., Bucht, G. and Gustafson, Y. (2001). Delirium before and after operation for femoral neck fracture. Fournal of the American Geriatrics Society, 49, 1335-1340.

Eikelenboom, P. and Hoogendijk, W. J. (1999). Do delirium and Alzheimer's dementia share specific pathogenetic mechanisms? Dementia E Geriatric Cognitive Disorders, 10, 319-324. doi: 10.1159/000017162

Fick, D. M., Agostini, J. V. and Inouye, S. K. (2002). Delirium superimposed on dementia: a systematic review. Fournal of the American Geriatrics Society, 50, 17231732.

Fick, D. and Foreman, M. (2000). Consequences of not recognizing delirium superimposed on dementia in hospitalized elderly individuals. Fournal of Gerontological Nursing, 26, 30-40.

Francis, J., Martin, D. and Kapoor, W. N. (1990). A prospective study of delirium in hospitalized elderly. fAMA, 263, 1097-1101.

Gustafson, Y. et al. (1988). Acute confusional states in elderly patients treated for femoral neck fracture. Fournal of the American Geriatrics Society, 36, 525-530.

Hernlund, E. et al. (2013). Osteoporosis in the European Union: medical management, epidemiology and economic burden. A report prepared in collaboration with the International Osteoporosis Foundation (IOF) and the European Federation of Pharmaceutical Industry Associations (EFPIA). Archives of Osteoporosis, 8, 136. doi:10.1007/s11657-013-0136-1

Hirsch, C. H., Sommers, L., Olsen, A., Mullen, L. and Winograd, C. H. (1990). The natural history of functional morbidity in hospitalized older patients. Fournal of the American Geriatrics Society, 38, 1296-1303.

Holroyd-Leduc, J. M. et al. (2010). A pragmatic study exploring the prevention of delirium among hospitalized older hip fracture patients: applying evidence to routine clinical practice using clinical decision support. Implementation Science, 5, 1-6. doi:10.1186/1748-5908-5-81

Holt, J. (1993). How to help confused patients. The American fournal of Nursing, 93, 32-36.

Hshieh, T. T. et al. (2015). Effectiveness of multicomponent nonpharmacological delirium interventions: a meta-analysis. $\mathcal{F A M A}$ Internal Medicine, 175, 512-20.

Inouye, S. K., Schlesinger, M. J. and Lydon, T. J. (1999). Delirium: a symptom of how hospital care is failing older persons and a window to improve quality of hospital care. The American fournal of Medicine, 106, 565-573.
Inouye, S. K., Wagner, D. R., Acampora, D., Horwitz, R. I., Cooney, L. M., Jr. and Tinetii, M. E. (1993). A controlled trial of a nursing-centered intervention in hospitalized elderly medical patients: the Yale geriatric care program. Fournal of the American Geriatrics Society, 41, 1353-1360.

Kalisvaart, C. J., Vreeswijk, R., de Jonghe, J. F. and Milisen, K. (2005). A systematic review of multifactorial interventions for primary prevention of delirium in the elderly. Tijdschrift voor Gerontologie en Geriatrie, 36, 224-231.

Kalisvaart, K. J. et al. (2005). Haloperidol prophylaxis for elderly hip-surgery patients at risk for delirium: a randomized placebo-controlled study. Fournal of the American Geriatrics Society, 53, 1658-1666. doi:10.1111/j.1532-5415.2005.53503.x

Leal, J. et al. (2016). Impact of hip fracture on hospital care costs: a population-based study. Osteoporosis International, 27, 549-558. doi: 10.1007/s00198-015-3277-9

Lerner, A. J., Hedera, P., Koss, E., Stuckey, J. and Friedland, R. P. (1997). Delirium in Alzheimer disease. Alzheimer Disease \& Associated Disorders, 11, 16-20.

Liu, S., Zhu, Y., Chen, W., Sun, T., Cheng, J. and Zhang, Y. (2015). Risk factors for the second contralateral hip fracture in elderly patients: a systematic review and meta-analysis. Clinical Rehabilitation, 29, 285-294. doi:10.1177/0269215514542358

Lundstrom, M., Edlund, A., Lundstrom, G. and Gustafson, Y. (1999). Reorganization of nursing and medical care to reduce the incidence of postoperative delirium and improve rehabilitation outcome in elderly patients treated for femoral neck fractures. Scandinavian fournal of Caring Sciences, 13, 193-200.

Lundstrom, M. et al. (2007). Postoperative delirium in old patients with femoral neck fracture: a randomized intervention study. Aging-Clinical E Experimental Research, 19(3), 178-186.

Magaziner, J. et al. (2000). Recovery from hip fracture in eight areas of function. The fournals of Gerontology. Series A, Biological Sciences and Medical Sciences, 55, M498-507.

Marcantonio, E. R. (2011). In the clinic. Delirium. Annals of Internal Medicine, 154(11), ITC6-1, ITC6-2, ITC6-3, ITC6-4, ITC6-5, ITC6-6, ITC6-7, ITC6-8, ITC6-9, ITC6-10, ITC16-11, ITC16-12, ITC16-13, ITC16-14, ITC16-15; quiz ITC16-16. doi: 10.7326/0003-4819-154-11-201106070-01006

Marcantonio, E. R., Flacker, J. M., Wright, R. J. and Resnick, N. M. (2001). Reducing delirium after hip fracture: a randomized trial. Fournal of the American Geriatrics Society, 49, 516-522.

Marks, R., Allegrante, J. P., Ronald MacKenzie, C. and Lane, J. M. (2003). Hip fractures among the elderly: causes, consequences and control. Ageing Research Reviews, 2, 57-93.

Martinez, F., Tobar, C. and Hill, N. (2015). Preventing delirium: should nonpharmacological, multicomponent interventions be used? A systematic review and meta-analysis of the literature. Age and Ageing, 44, 196-204.

McCusker, J., Cole, M., Dendukuri, N., Belzile, E. and Primeau, F. (2001). Delirium in older medical inpatients 
and subsequent cognitive and functional status: a prospective study. CMAF, 165, 575-583.

Milisen, K. et al. (2001). A nurse-led interdisciplinary intervention program for delirium in elderly hip-fracture patients. Fournal of the American Geriatrics Society, 49, 523-532.

Moran, C. G., Wenn, R. T., Sikand, M. and Taylor, A. M. (2005). Early mortality after hip fracture: is delay before surgery important? The fournal of Bone $\mathcal{E}$ foint Surgery, 87, 483-489. doi: 10.2106/JBJS.D.01796

Morency, C. R. (1990). Mental status change in the elderly: recognizing and treating delirium. Fournal of Professional Nursing, 6, 356-364; discussion 364-355.

Overshott, R., Karim, S. and Burns, A. (2008). Cholinesterase inhibitors for delirium. Cochrane Database of Systematic Reviews (1), CD005317. doi:10.1002/14651858.CD005317.pub2

Rae, H. C., Harris, I. A., McEvoy, L. and Todorova, T. (2007). Delay to surgery and mortality after hip fracture. ANZ Fournal of Surgery, 77, 889-891. doi:10.1111/j.1445-2197.2007.04267.x

Rockwood, K., Cosway, S., Carver, D., Jarrett, P., Stadnyk, K. and Fisk, J. (1999). The risk of dementia and death after delirium. Age and Ageing, 28, 551-556.

Siddiqi, N., Stockdale, R., Britton, A. M. and Holmes, J. (2007). Interventions for preventing delirium in hospitalised patients. Cochrane Database of Systematic Reviews, CD005563. doi:10.1002/14651858.CD005563.pub2

Svensson, O., Stromberg, L., Ohlen, G. and Lindgren, U. (1996). Prediction of the outcome after hip fracture in elderly patients. The fournal of Bone E foint Surgery, 78, 115-118.

Thomas, E., Smith, J. E., Forrester, D. A., Heider, G., Jadotte, Y. T. and Holly, C. (2014). The effectiveness of non-pharmacological multi-component interventions for the prevention of delirium in non-intensive care unit older adult hospitalized patients: a systematic review. The fBI Database of Systematic Reviews and Implementation Reports, 12(4), 180-232. doi:10.11124/jbisrir-2014-1446

Wanich, C. K., Sullivan-Marx, E. M., Gottlieb, G. L. and Johnson, J. C. (1992). Functional status outcomes of a nursing intervention in hospitalized elderly. Fournal of Nursing Scholarship, 24, 201-207.

Watne, L. O. et al. (2014). The effect of a pre- and postoperative orthogeriatric service on cognitive function in patients with hip fracture: randomized controlled trial (Oslo Orthogeriatric Trial). BMC Medicine, 12, 63. doi: https://doi.org/10.1186/1741-7015-12-63

Wong, D. M., Niam, T., Bruce, J. J. and Bruce, D. G. (2005). Quality project to prevent delirium after hip fracture. Australasian fournal on Ageing, 24(3), 174-177. doi: https://oi.org/10.1111/j.1741-6612.2005.00108.x

Yang, Y., Zhao, X., Dong, T., Yang, Z., Zhang, Q. and Zhang, Y. (2017). Risk factors for postoperative delirium following hip fracture repair in elderly patients: a systematic review and meta-analysis. Aging Clinical and Experimental Research, 29, 115-126. doi:10.1007/s40520-016-0541-6

Zimberg, M. and Berenson, S. (1990). Delirium in patients with cancer: nursing assessment and intervention. Oncology Nursing Forum, 17, 529-538. 